Грудкіна Н. С.

\title{
ОЦНКА ФОРМОУТВОРЕННЯ ПОРОЖНИСТИХ ДЕТАЛЕЙ 3 ФЛАНЦЕМ У ПРОЦЕСІ РАДІАЛЬНО-ЗВОРОТНОГО ВИДАВЛЮВАННЯ ЕНЕРГЕТИЧНИМ МЕТОДОМ
}

Оцінка конкурентоспроможності продукції галузей машинобудування в сучасних умовах нерозривно пов'язана з розробкою і освоєнням нових технологій. У зв'язку з цим зростає роль таких ефективних ресурсозберігаючих процесів обробки металів тиском, як холодне об'ємне штампування (ХОШ). Технологічні способи ХОШ відрізняються різноманіттям можливостей і високою ефективністю в порівнянні з іншими процесами формоутворення деталей, при цьому процеси видавлювання демонструють стійку тенденцію до збільшення обсягів виробництва точних заготовок та розширенню номенклатури як штампованих деталей, так і матеріалів [1]. Комбіноване видавлювання при виробництві деталей з фланцем та відростками підвищує технологічні можливості процесів штампування, однак характеризується недостатнім освітленням в літературі досліджень як силового режиму, так і чітких рекомендацій щодо прогнозування поетапного формоутворення напівфабрикату [2].

Аналіз впливу геометричних параметрів процесів комбінованого видавлювання 3 декількома степенями свободи течії металу на даний час в основному проведений на основі методу скінченних елементів (МСЕ) та характеризується відсутністю аналітичних залежностей силових параметрів процесу та формоутворення заготовки [3, 4]. 3 іншого боку ефективним теоретичним методом дослідження процесів комбінованого видавлювання з декількома степенями свободи течії металу є енергетичний метод верхньої оцінки. Ключовими етапами його застосування можна вважати підбір функцій, що описують кінематично можливе поле швидкості (КМПШ) та інструментів спрощення складових енергетичного рівняння, що дозволяють отримувати приведений тиск у аналітичному вигляді. Це стосується перш за все розрахункових схем, що містять трапецеїдальні модулі з криволінійними границями. Перші спроби вирішити проблеми спрощення розрахунків потужності сил деформування стосувалися можливості використання лінеаризації інтенсивності швидкостей деформації $[5,6]$. Однак неефективність їхнього використання при моделюванні процесів комбінованого радіально-зворотного видавлювання грунтується на неможливості обрати відповідну заміну, єдину у межах кінематичного модуля [7].

Одним 3 ефективних прийомів спрощення розрахунків приведеного тиску є пошук спеціальних функцій або цілого сімейства функцій, які описують похилу криволінійну границю кінематичного модуля та дозволяють отримати потужності сил деформування, тертя i зрізу в аналітичному вигляді [8]. Цей метод грунтується на використанні функцій, що є розв'язком диференціального рівняння, яке дозволяє отримати вираз інтенсивності швидкостей деформації у вигляді, прийнятному для подальшого інтегрування за областю кінематичного модуля. Подальша оптимізація функції приведеного зусилля деформування за кінематичними параметрами надає можливість прогнозування формоутворення деталі. Однак даний прийом раціонально застосовувати для осьових трапецеїдальних кінематичних модулів з похилою границею у вигляді $T=T(z)[7,8]$.

Іншим прийомом спрощення складових приведеного тиску деформування є застосування оцінки згори потужності сил деформування за формулами Коші-Буняковського або кубатурними формулами. За таких умов можливе подальше отримання розрахункових формул оптимального значення кінематичних параметрів та приростів напівфабрикату. Однак при використанні прийомів спрощення складових приведеного тиску деформування необхідно контролювати відповідність дійсності як енергосилового режиму, так і формоутворення заготовки [7]. 
Таким чином, пошуки шляхів отримання інженерних формул розрахунків приростів отримуваної деталі, що відповідають дійсності та не викликають труднощів під час використання, визначає коло основних задач теоретичних досліджень процесів комбінованого видавлювання.

Метою роботи є аналіз впливу використання прийомів спрощення складових приведеного тиску деформування на оцінку формоутворення порожнистих деталей типу стакану 3 фланцем у процесах комбінованого радіально-зворотного видавлювання.

Розглянемо розрахункову схему процесу комбінованого радіально-зворотного видавлювання порожнистих деталей з фланцем (рис. 1). Наявність трапецеїдального кінематичного модуля 2 з похилою прямолінійною границею призводить до неможливості отримання у вигляді аналітичної функції потужності пластичної деформації. Використання лінеаризації інтенсивності швидкостей деформації виявляється неефективним з огляду на неможливість обрати відповідну заміну, дійсну у всьому об’ємі кінематичного модуля.

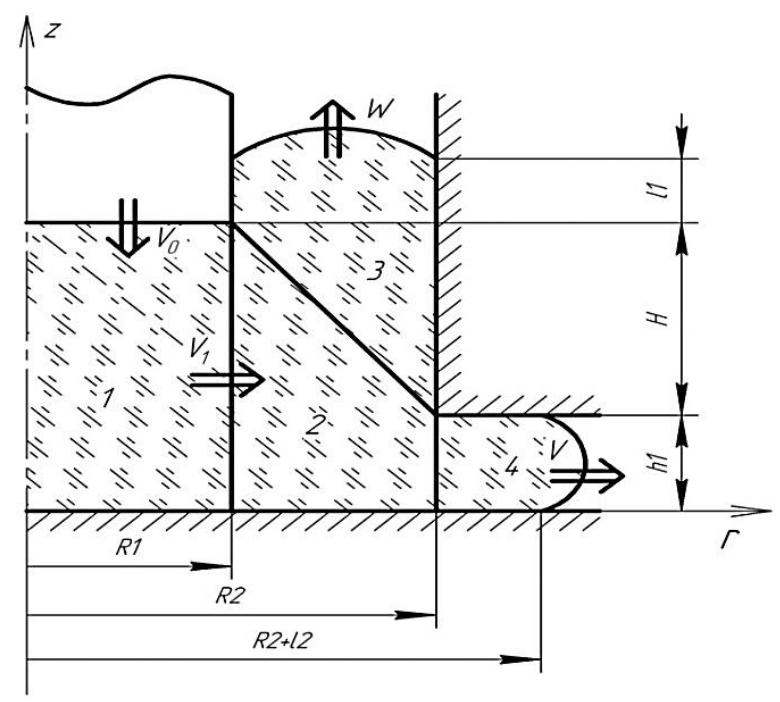

Рис. 1. Розрахункова схема процесу комбінованого радіально-зворотного видавлювання деталей з фланцем [7]

Наведемо вигляд похилої прямолінійної границі кінематичного модуля 2:

$$
z(r)=a(r+b), a=\frac{H}{R_{1}-R_{2}}, \quad b=\frac{h_{1}}{a}-R_{2}, M=V_{0} R_{1}^{2} .
$$

Складова приведеного тиску деформування у зоні 2 в загальному вигляді:

$$
\begin{aligned}
& \bar{p}_{N_{\partial 2}}=\frac{2}{\sqrt{3} R_{1}^{2}} \int_{R_{1}}^{R_{2}} r d r \int_{0}^{G(r)} \sqrt{4\left(\dot{\varepsilon}_{z 2}^{2}+\frac{v_{r 2}}{r} \dot{\varepsilon}_{z 2}+\frac{v_{r 2}^{2}}{r^{2}}\right)+\left(\left(2 \dot{\varepsilon}_{z 2}+\frac{v_{r 2}}{r}\right) \frac{a z}{z(r)}\right)^{2}} d z, \\
& \text { де } v_{r 2}=\frac{M+W\left(R_{1}^{2}-r^{2}\right)}{2 r z(r)}, \dot{\varepsilon}_{z 2}=\frac{W+a v_{r 2}}{z(r)} .
\end{aligned}
$$

Використання верхньої оцінки за формулою Коші - Буняковського дозволило отримати вираз складових приведеного тиску деформування у зоні 2 у вигляді:

$$
V_{2}=2 \pi \int_{R_{0}}^{R} r d r \int_{0}^{z(r)} d z=2 \pi a\left(\frac{R_{2}{ }^{3}-R_{1}^{3}}{3}+b \frac{R_{2}{ }^{2}-R_{1}^{2}}{2}\right),
$$




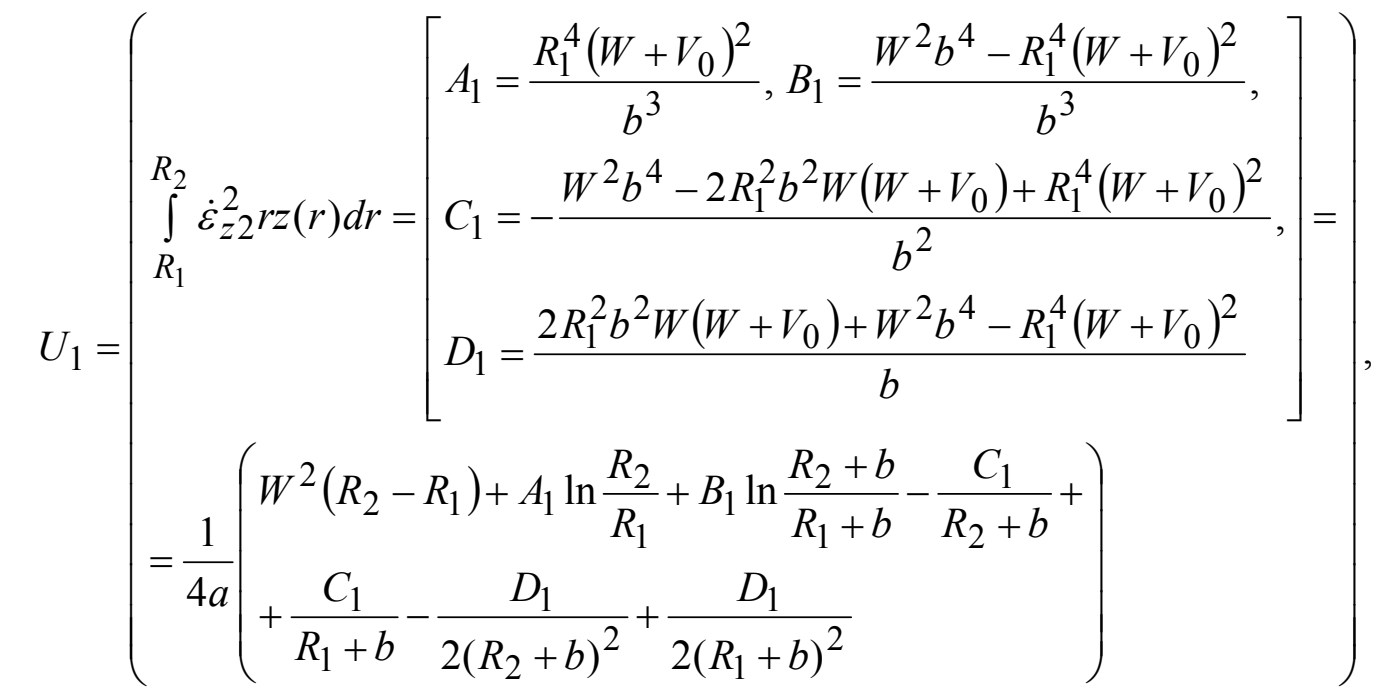

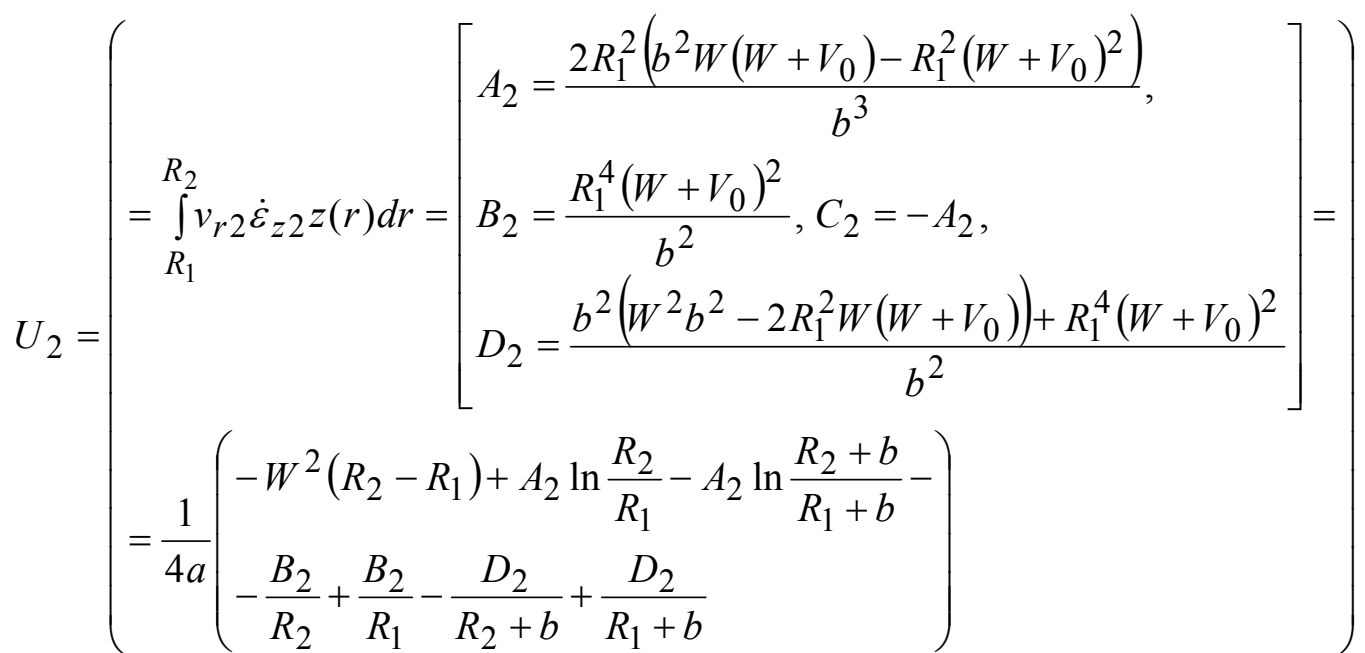

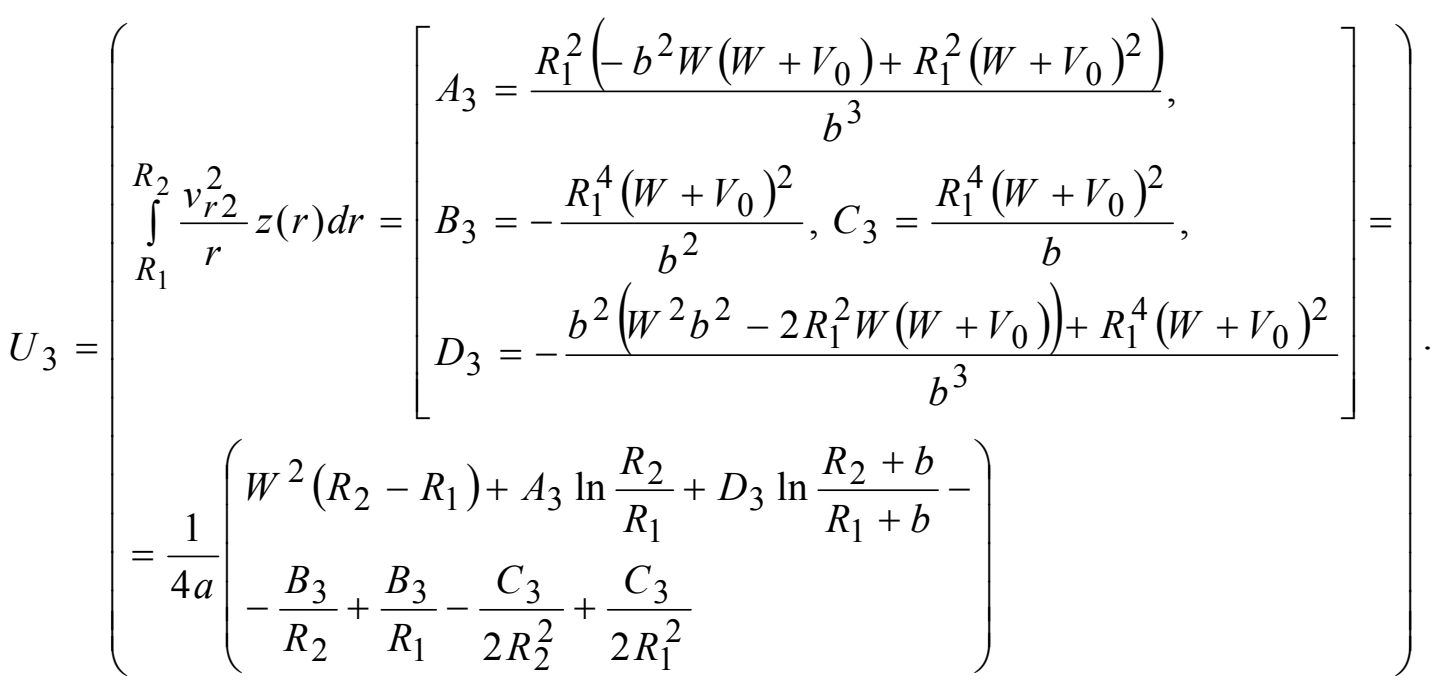

Тоді за формулами (2)-(5) остаточно отримаємо верхню оцінку приведеного тиску деформування у зоні 2 у аналітичному вигляді:

$$
\bar{p}_{N_{\partial 2}} \leq \frac{2 \pi \sigma_{S}}{\sqrt{3}} \sqrt{a\left(\frac{R_{2}^{3}-R_{1}^{3}}{3}+b \frac{R_{2}^{2}-R_{1}^{2}}{2}\right)\left(4\left(1+\frac{a^{2}}{3}\right)\left(U_{1}+U_{2}\right)+\left(4+\frac{a^{2}}{3}\right) U_{3}\right)} .
$$


Отримання величини приведеного тиску кінематичного модуля 2 у вигляді (6) значно спрощує отримання величини повного приведеного тиску деформування процесу комбінованого радіально-зворотного видавлювання деталей з фланцем. При цьому визначення оптимального значення швидкості витікання металу у вертикальному напрямку теж не викликає труднощів та дозволяє отримати дані про поетапне формоутворення напівфабрикату. Але використання наближеної верхньої оцінки (6) силових параметрів процесу з одного боку спрощує розрахунки з похибкою обчислень, що не перевищує $2-5 \%$, а 3 іншого боку може призводити до зміщеної оцінки оптимальних кінематичних параметрів процесу деформування. А це в свою чергу може спричинити похибки при прогнозуванні розмірів деталі, тому необхідним є проведення обов'язкового аналізу впливу використання верхньої оцінки силових параметрів на отримання даних щодо формоутворення, які відповідають дійсності. Проведемо дослідження величин складових приведеного тиску деформування у загальному вигляді за допомогою чисельних обчислень та з використанням верхньої оцінки у формі (6). Порівняльний аналіз залежностей приведеного тиску деформування у зоні 2 верхньої оцінки у вигляді кривої (1) та аналітичному вигляді за допомогою чисельних розрахунків (крива (2)) підтверджує подібний характер функцій $\bar{p}_{N_{\partial 2}}=\bar{p}_{N_{\partial 2}}(\bar{W})$ від відносного кінематичного параметру $\bar{W}=W / V_{0}$ для параметрів процесу: $R_{1}=10.5, R_{2}=22.5, H=7$ (рис. 2, а). Для даної розрахункової схеми процесу труднощі виникають лише для визначення потужності сил деформування у зоні 2, інші складові приведеного тиску для прямолінійної похилої границі знайдені у аналітичному вигляді [7]. Тому використовуючи наведені вище формули обчислень (1) та (6), можна отримати величину повного приведеного тиску деформування та його верхньої оцінки для зазначених геометричних параметрів процесу деформування (рис. 2, б).

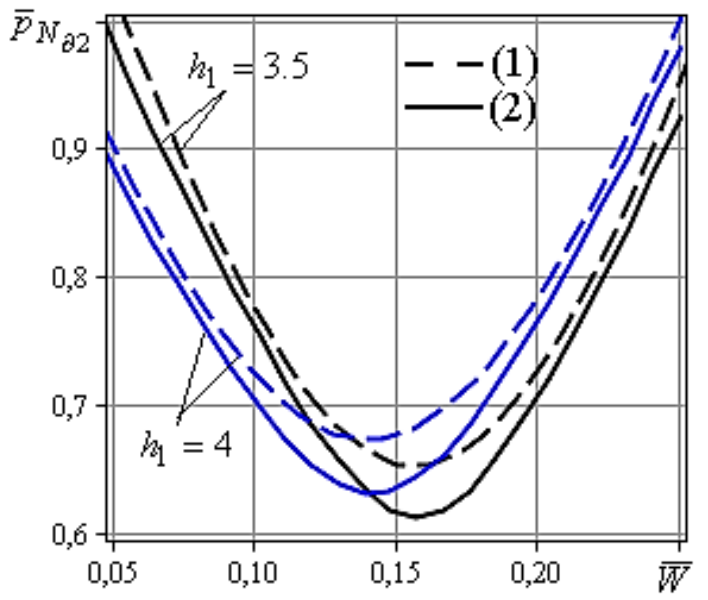

a

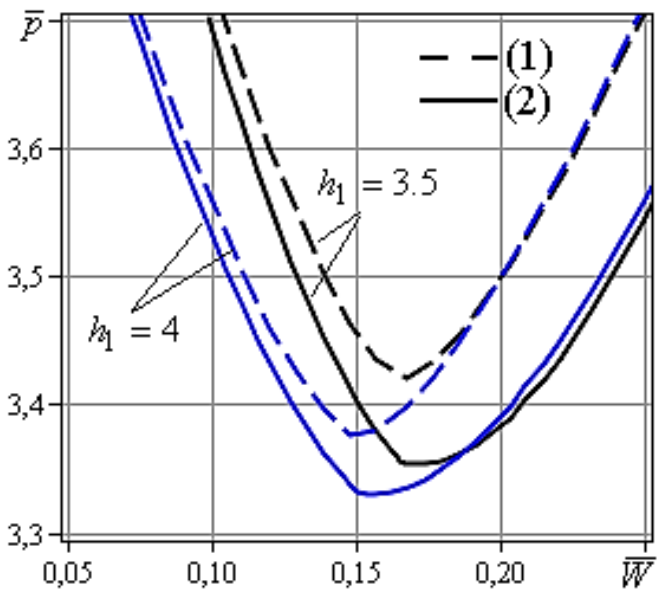

6

Рис. 2. Порівняльний аналіз розрахункових залежностей для верхньої оцінки (1) та загального вигляду (2):

a - приведеного тиску у зоні 2; б - повної величини приведеного тиску деформування

Подібність кривих, отриманих для величини приведеного тиску деформування та його верхньої оцінки, зберігається для різних наборів геометричних параметрів процесу деформування. При цьому маємо наявність точки мінімуму, яка відповідає оптимальному значенню відносного кінематичного параметра, що зменшується при збільшенні висоти фланцю. Відмінність оптимальних значень відносної швидкості витікання металу у вертикальному напрямку для обчислення за формулою (1) та наближеного значення (6) складає 1-1,5% і може вважатися несуттєвою. Перевищення величини приведеного тиску деформування у зоні 2 може досягати 5-8 \%, але для величини повного приведеного тиску деформування даної розрахункової схеми значно зменшується і складає не більше 1-3\%. 
Отримане оптимальне значення швидкості витікання металу у вертикальному напрямку визначає прирости стінки стакану та з умови рівності об'ємів і величину заповнення фланцевої зони. Відмінність у обчисленнях відносного кінематичного параметра може впливати на достовірність даних щодо прогнозування формоутворення напівфабрикату. Тому особливу увагу слід приділити саме порівнянню теоретичних та експериментальних даних приростів заготовки у процесі деформування.

Окремо проведено порівняльний аналіз формоутворення стінки стакану за допомогою даної розрахункової схеми та експериментальних даних для матеріалу С1 при $R_{1}=10.5, R_{2}=18, h_{1}=4.1, H_{0}=16.1$ (рис. 3 ).

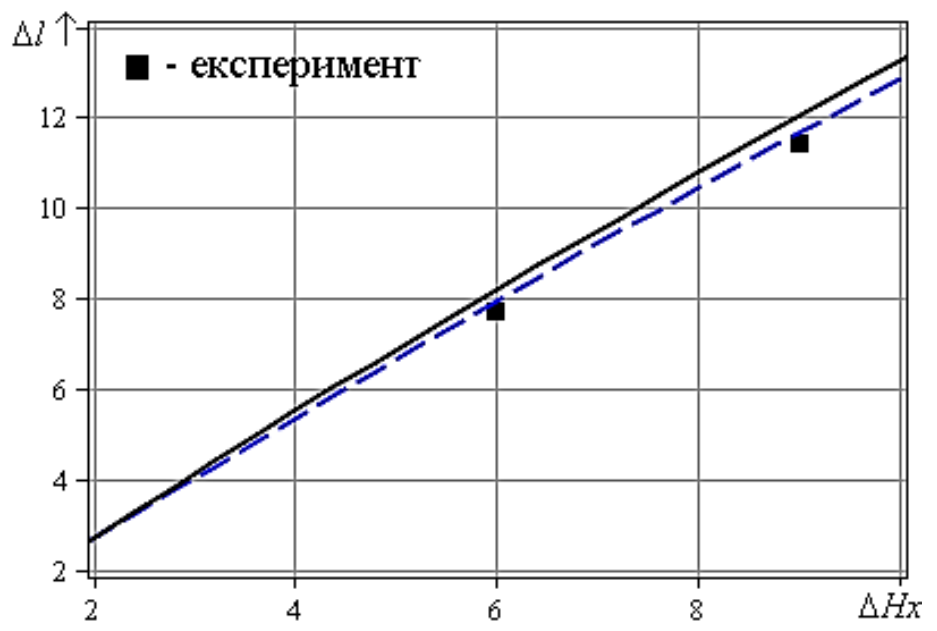

Рис. 3. Порівняльний аналіз теоретично та експериментально отриманих розмірів деталі за ходом процесу

Відхилення теоретично отриманих розмірів стінки стакану за ходом процесу на основі чисельних розрахунків та верхньої оцінки від експериментально отриманих точкових значень не перевищує 3-7 \%. При цьому незначна взаємна розбіжність теоретично отриманих результатів пояснюється зміщенням оптимального значення відносного кінематичного параметра, що і відповідає за формування приросту напівфабрикату у вертикальному напрямку. Таким чином, використання верхньої оцінки за допомогою формули Коші-Буняковського істотно не впливає на отримання даних щодо формоутворення та може вважатися ефективним прийомом спрощення складових приведеного тиску та прогнозування розмірів отримуваної деталі.

\section{ВИСНОВКИ}

Проведено порівняльний аналіз величини складових приведеного тиску деформування як функції швидкості витікання металу у вертикальному напрямку з використанням чисельних розрахунків та верхньої оцінки за Коші-Буняковським на основі розрахункової схеми комбінованого радіально-зворотного видавлювання деталей 3 фланцем. Проаналізовано вплив на величину оптимального кінематичного параметру спрощення складових приведеного тиску деформування. Встановлено, що характер теоретично отриманих кривих приведеного тиску зберігається із зміною величини фланцю, а перевищення з використанням спрощеної оцінки складає не більше 1-3\%. Незначна взаємна розбіжність теоретично отриманих результатів пояснюється незначним зміщенням оптимального значення відносного кінематичного параметра, який відповідає за величину приросту напівфабрикату у вертикальному напрямку. Підтверджено, що використання верхньої оцінки істотно не впливає на отримання даних щодо формоутворення та може вважатися ефективним прийомом спрощення складових приведеного тиску та прогнозування розмірів отримуваної деталі. 


\section{СПИСОК ВИКОРИСТАНОЇ ЛІТЕРАТУРИ}

1. Zhang S.H., Wang Z.R. Some new features in the development of metal forming technology. Journal of Materials Processing Technology. 2004. № 1, pp. 39-47.

2. Алиева Л.И. Процессы комбинированного выдавливания и деформирования. Обработка материалов давлением. Краматорск : ДГМА. 2016. 1 (42). С. 100-108.

3. Farhoumand A., Ebrahimi R. Analysis of forward-backward-radial extrusion process. Materials and Design. 2009. 30, pp. 2152-2157.

4. Головин В.А., Филиппов Ю.К., Игнатенко В.Н. Особенности кинематики течения металла при комбинированном холодном выдавливании полых деталей с фланцем заданных размеров. Приоритеты развития отечественного автотракторостроения и подготовки инженерных и научных кадров: материалы 49-й Международной научно-технической конференции. Москва: МАМИ. 2005. Часть 2. С. 18-20.

5. Степанский Л. Г. Расчеты процессов обработки металлов давлением. Москва: Машиностроение. 1979. $215 \mathrm{c}$.

6. Чудаков П.Д. О вычислении мощности пластической деформации. Известия вузов. Машиностроение. 1979. 7. С. $146-148$.

7. Алиева Л.И., Грудкина Н.С., Крюгер К. Моделирование процесса радиально-обратного выдавливания полых деталей. Mechanics and Advanced Technologies. $2017 . \quad 1$ (79). С. 91-99. DOI: http://dx.doi.org/10.20535/2521-1943.2017.79.95873.

8. Vlasenko K., Hrudkina N., Reutova I., Chumak O. Development of calculation schemes for the combined extrusion to predict the shape formation of axisymmetric parts with a flange. Eastern European Journal of Enterprise Technologies. 2018. 3/1 (93), pp. 51-59. DOI: https://doi.org/10.15587/1729-4061.2018.131766

\section{REFERENCES}

1. Zhang S.H., Wang Z.R. Some new features in the development of metal forming technology. Journal of Materials Processing Technology. 2004. 1. pp. 39-47.

2. Aliieva L.I. Processes of combined extrusion and deformation. Materials Working by Pressure. Kramatorsk: DSEA. 2016, 1 (42), pp. 100-108. (in Russian).

3. Farhoumand A., Ebrahimi R. Analysis of forward-backward-radial extrusion process. Materials and Design. 2009, 30, pp. 2152-2157.

4. Golovin V.A., Filippov Yu. K., Ignatenko V.N. Features of the kinematics of metal flow during combined cold extrusion of hollow parts with a flange of a given size. Proceedings of the 49th International Conference. Moscow: MAMI, 2005, part 2, pp. 18-20. (in Russian). (in Russian).

5. Stepansky L.G. Calculations of metal forming processes. Moscow: Mechanical Engineering. 1979, 215 p.

6. Chudakov P.D. On the calculation of the power of plastic deformation, Izvestiya. Engineering. 1979, 7, pp. 146-148. (in Russian).

7. Aliieva L.I., Grudkina N.S., Krueger K. Modeling of the process of radial backward extrusion of hollow parts. Bulletin of NTUU "KPI". Mechanics and Advanced Technologies. 2017, 1 (79), pp.91-99. DOI: http://dx.doi.org/10.20535/2521-1943.2017.79.95873 (in Russian).

8. Vlasenko K., Hrudkina N., Reutova I., Chumak O. Development of calculation schemes for the combined extrusion to predict the shape formation of axisymmetric parts with a flange. Eastern European Journal of Enterprise Technologies. 2018, 3/1 (93), pp. 51-59. DOI: https://doi.org/10.15587/1729-4061.2018.131766

Грудкіна Н. С. - канд. техн. наук, доц., докторант ДДМА

ДДМА - Донбаська державна машинобудівна академія, м. Краматорськ.

E-mail: vm.grudkina@ukr.net. 